BIOTROPIA No. 8, 1995: 45-52

\title{
EFFECTS OF PISOLITHUS TINCTORIUS AND LACCARIA FRATERNA ON THE GROWTH AND MYCORRffIZAL DEVELOPMENT OF PINUSPATULA SEEDLINGS*)
}

\author{
M. SUDHAKARA REDDY and K. NATARAJAN \\ Centre for advanced Studies in Botany, University of Madras, \\ Guindy Campus, Madras 600 025, India
}

\begin{abstract}
Vegetative inoculum of Pisolithus tinctorius and Laccariafraterna were inoculated to Pinuspatula seedlings grown in both steam sterilized and unsterilized shola soil. After 4 months of seedling growth, 10 seedlings from each treatment were harvested and various growth parameters were studied. Inoculation of these two fungi resulted in the production of ectomycorrhizas and increase in growth of $P$. patula seedlings when compared to uninoculated seedlings. Laccariafraterna inoculated seedlings showed more number of mycorrhizas than $P$. tinctorius inoculated seedlings at the end of one year. Both these fungi poorly colonized the root system in both soil treatments. There was no significant difference between these two fungi in improving the seedling growth in the nursery.
\end{abstract}

Key words: Pisolithus tinctorius/Laccaria fraterna/Pinus patula/Inoculum/Seedlings/Growth.

\section{INTRODUCTION}

Extensive work on nursery inoculation has been done with Pisolithus tinctorius because of its ecological adaptation to adverse soil conditions, wide geographic distribution and broad host range, tolerance to a variety of environmental conditions and its easy propagation and manipulation in pure culture (Marx et al. 1984). Eventhough $P$. tinctorius is worldwide in distribution and has a broad tree host range it has not been found in the Nilgiri hills either in pine or eucalypt plantations. The other potential ectomycorrhizal fungus Laccariafraterna is wide spread throughout the world where Eucalyptus and other ectomycorrhizal hosts have been introduced (Tommerup et al. 1991). At certain places in Nilgiri hills where eucalypt and pine plantations occur side by side, $L$. fraterna is mostly found to be associated with the eucalypts but rarely with pines (Natarajan 1977). But under in vitro condition these two fungi were able to form mycorrhizas with $P$. patula seedlings. The present research study was undertaken to study the effects of these two fungi on the growth and mycorrhizal development of $P$. patula seedlings in the nursery.

\footnotetext{
*)Paper presented at the Second Symposium on Biology and Biotechnology of Mycorrhizae and Third Asian Conference on Mycorrhizae (ACOM III), 19-21 April 1994, Yogyakarta, Indonesia.
} 


\section{MATERIALS AND METHODS}

Pisolithus tlnctorius culture was isolated from basidiomata collected from Eucalyptus tereticornis plantations, near Madras coast, Tamilnadu and the culture of $L$. fraterna was isolated from the basidiomata collected from $E$. globulus plantations in Nilgiri hills, Tamilnadu, South India. The cultures were maintained at $25^{\circ} \mathrm{C}$ on potato dextrose agar medium.

The mycelial inoculum of $P$. tinctorius and $L$. fraterna were prepared according to the method of Marx and Bryan (1975). Inoculum of each fungus was grown aseptically in one litre Erlenmeyer flasks containing $750 \mathrm{ml}$ of vermiculite moistened with $375 \mathrm{ml}$ of MMN liquid medium. The flasks were incubated at $25^{\circ} \mathrm{C}$ in dark. After 12 weeks of incubation, inoculum was removed from the flask and leached with cool running tap water to remove the unused nutrients. Excess free water was removed by gently squeezing the inoculum wrapped in cheese cloth. Fungus free vermiculite wih MMN served as control.

The shola soil collected under natural vegetation of the upper region of Nilgiri hills was used in the present study. The chemical constituents of the soil are as follows: $\mathrm{pH}-5.3$; Organic matter content $-4.79 \%$; NPK levels - 245, 5.2 and $35 \mathrm{~kg} /$ acre, respectively. The nursery experiment was conducted at the Forest Department Nursery, Ootacamund, Nilgiri hills during July 1992 to June 1993. Both steam sterilized and unsterilized soils were filled in polybags (about $2 \mathrm{~kg} / \mathrm{bag}$ ) and 10\% inoculum by volume was added to the polybags separately and mixed into the upper $8-10 \mathrm{~cm}$ of the soil. Fungus free vermiculite added to the polybags served as controls. The surface sterilized seeds of $P$. patula $\left(30 \% \mathrm{H}_{2} \mathrm{O}_{2}\right.$ for 30 minutes) were sown in all the bags. Five (5) seeds were sown in each bag. After germination, seedlings were thinned to one per bag. Ten (10) replicates were kept for each treatment. After 12 months of seedling growth, 10 seedlings from each sample were harvested and the growth and mycorrhizal development were studied. The shoot height, root length, and root collar diameter were measured. After counting the mycorrhizal and non-mycorrhizal tips, the shoots and roots were dried in a hot air oven at $85^{\circ} \mathrm{C}$ for 48 hours. Dry weights of shoot and root were determined by obtaining constant weights. The method used by Zak (1973) and Agerer (1986) were followed for studying the macroscopic and microscopic features of ectomycorrhizas. The colour terminology used is that of Kornerup and Wanscher (1978). All the data were analysed by analysis of variance and the means were compared by least significant difference (Snedecor and Cochran 1967) at $\mathrm{P}=0.05$ level. 


\section{RESULTS}

The root examinations revealed that both the ectomycorrhizal fungi viz., $P$. tinctorius and $L$. fraterna were able to form mycorrhizas with $P$. patula seedlings in the nursery.

The $P$. tinctorius type of mycorrhizas are mostly dichotomous, tetrapodials and coralloid forms, 3-6 mm long and 0.4-0.5 mm in diameter. Colour of mycorrhizas are brownish yellow (5C8) to light brown (6D6). Loose hyaline hyphae are associated with the surface of the mycorrhizal system. The rhizomorphs are light brown (6D6) in colour and 150-550 $\mu \mathrm{m}$ wide, composed of closely packed parallel hyphae and covered with

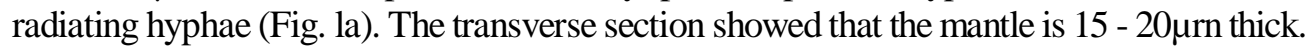
It consists of a simple prosenchymatous tissue. Cystidia, setae or sclerotia are not observed. The Hartig net is composed of one or two rows of oval to globose hyphal cells which measure $5-10 \mu \mathrm{m}$ in thickness and penetrate up to 4 cortical cell layers deep (Fig. $\mathrm{Ib})$.

Laccaria fraterna type of mycorrhizas are mostly bipodial, rarely monopodial, 3-5 $\mathrm{mm}$ long and $0.3-0.4 \mathrm{~mm}$ in diameter. Colour of the mycorrhizas are orange white (6A2) when young and brown (6D7) when old. The surface is smooth. Rhizomorphs are absent (Fig. Ic). The transverse section showed a mantle of $10-15 \mu \mathrm{m}$ thick and consists of a simple prosenchymatous tissue. The Hartig net is composed of a single row of oval to globose hyphal cells which measure 3 - $6 \mu \mathrm{m}$ in thickness and penetrate up to 3 cortical cell layers deep (Fig. Id).

Inoculation of $P$. tinctorius and $L$. fraterna increased the number of mycorrhizas both in sterilized and unsterilized soil. The number of mycorrhizas were more in sterilized inoculated soil than in unsterilized soil. Laccaria fraterna produced more number of mycorrhizas than $P$. tinctorius. But there was no significant difference between these two fungi. The percentage of mycorrhizas did not differ significantly between $P$. tinctorius and $L$. fraterna inoculated seedlings in both soil treatments. The percent colonization of both inoculated fungi were lower in both soil treatments. When compared to $P$. tinctorius, $L$. fraterna inoculated seedlings showed higher percent colonization at the end of one year. No basidiomata production was seen in the case of $P$. tinctorius whereas $L$. fraterna inoculated seedlings produced basidiomata in the bags at the end of one year.

The growth of $P$. patula seedlings was improved in both sterilized and unsterilized soil by the inoculation of the fungi. The shoot height was more in sterilized inoculated soil than in unsterilized inoculated soil. But there was no significant difference between the two fungi in improving the shoot height. The root length has increased in both soils by the inoculation of these two fungi. Laccaria fraterna inoculated seedlings showed a higher root collar diameter when compared to $P$. tinc- 
BIOTROPIA No. 8, 1995
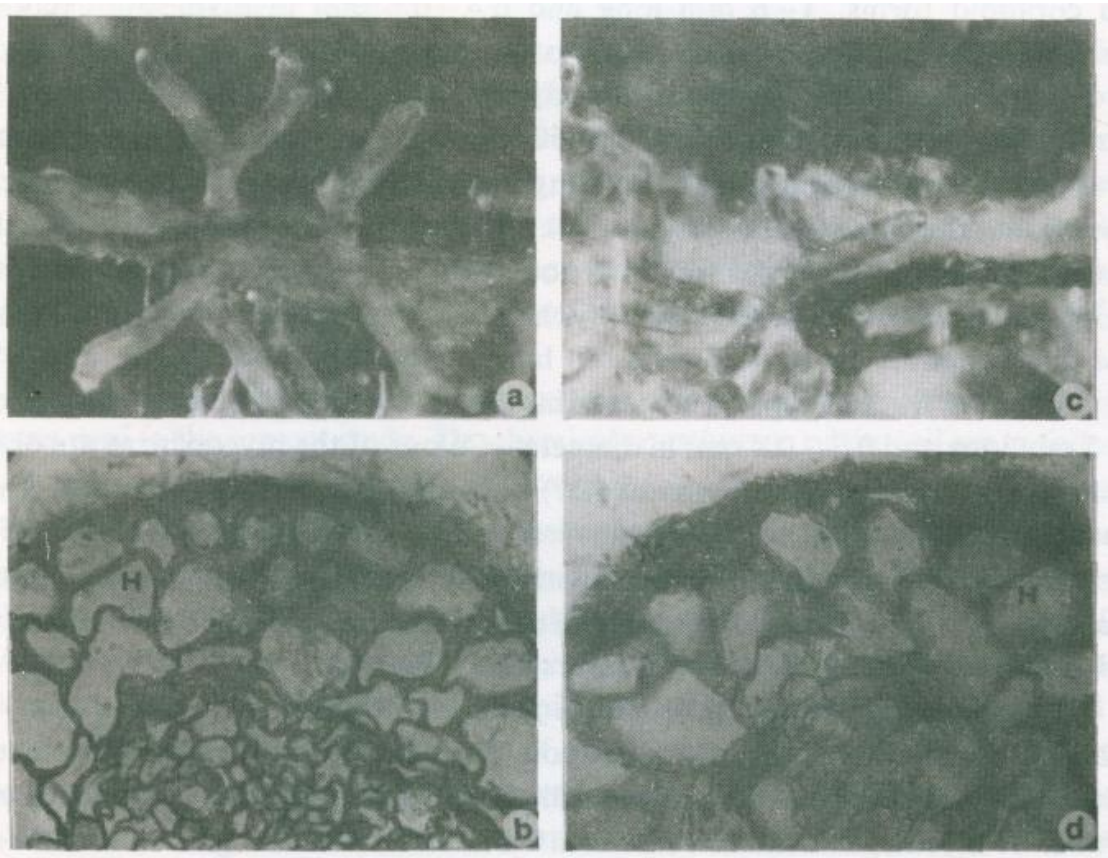

Figure 1. Ectomycorrhizas of Pinus patula produced by Pisolithus tinctorius and Laccaria fraterna.

a. Morphology of $P$. tinctorius ectomycorrhizas x 240 .

b. Transverse section of $P$. tinctorius ectomycorrhizas $\mathrm{x} 320$.

c. Morphology of $L$. fraterna ectomycorrhizas $\mathrm{x} 200$.

d. Transverse section of $L$. fraterna ectomycorrhizas x 325 .

M - Mantle; H - Hartig net. 
torius inoculated seedlings. The shoot dry weight was more in sterilized soil than in unsterilized soil in inoculated seedlings. The seedlings inoculated with $L$. fraterna showed maximum shoot dry weight in both soils. But there was no significant difference between the two fungi in improving the shoot dry weight. The root dry weight also did not differ significantly between the two fungi. The shoot/root ratio differed significantly in control seedlings than in inoculated seedlings in sterilized soil. In unsterilized soil there was no significant difference between the two fungi and control seedlings with respect to the shoot/root ratio (Table 1).

Seedlings grown in sterilized soil inoculated with the two fungi showed more growth and mycorrhizal development than the seedlings grown in unsterilized soil inoculated with these fungi. Laccaria fraterna and $P$. tinctorius did not differ significantly in improving the growth and mycorrhizal development of $P$. patula seedlings in the nursery.

\section{DISCUSSION}

Since $P$. tinctorius and $L$. fraterna are known to be early stage ectomycorrhizal fungi (Marx 1991; Tommerup et al. 1991), these two species have been selected to evaluate their effects on the growth and mycorrhizal development of $P$. patula in the present study. Vegetative inoculum of these two fungi improved the growth and mycorrhizal development of $P$. patula seedlings when compared to uninoculated seedlings in the nursery in both steam sterilized and unsterilized soil. But the difference in various growth parameters is not significant in the inoculated seedlings. The seedlings inoculated with $L$. fraterna seem to be marginally better than the seedlings inoculated with $P$. tinctorius. Tommerup et al. (1991) reported that L. fraterna, an early colonizing mycorrhizal fungus of Eucalyptus is a potential competitor when the seedlings were inoculated with other selected ectomycorrhizal fungi. It is interesting to note that basidiomata of L. fraterna very rarely occur in $P$. patula plantations in Nilgiri hills and found mostly associated with Eucalyptus plantations which are adjacent to the $P$. patula plantations. It has also been noticed that basidiomata of $L$. laccata, the most predominant fungus in $P$. patula plantations, were seldom found in the Eucalyptus plantations. The results of the present experiment suggest that $L$. fraterna and $P$. tinctorius are capable of improving the growth of nursery seedlings in Nilgiri conditions. The colonization of these two fungi was poor in both treatments.

Marx and Cordell (1987) found that $\mathrm{pH}$ between 4.5 and 5.5 is adequate for $P$. tinctorius, but that a $\mathrm{pH}$ above 6.0 inhibits ectomycorrhizal formation. The $\mathrm{pH}$ of the soil used in the present study is 5.3 and hence it may not be the factor for 
BIOTROPIA No. 8, 1995

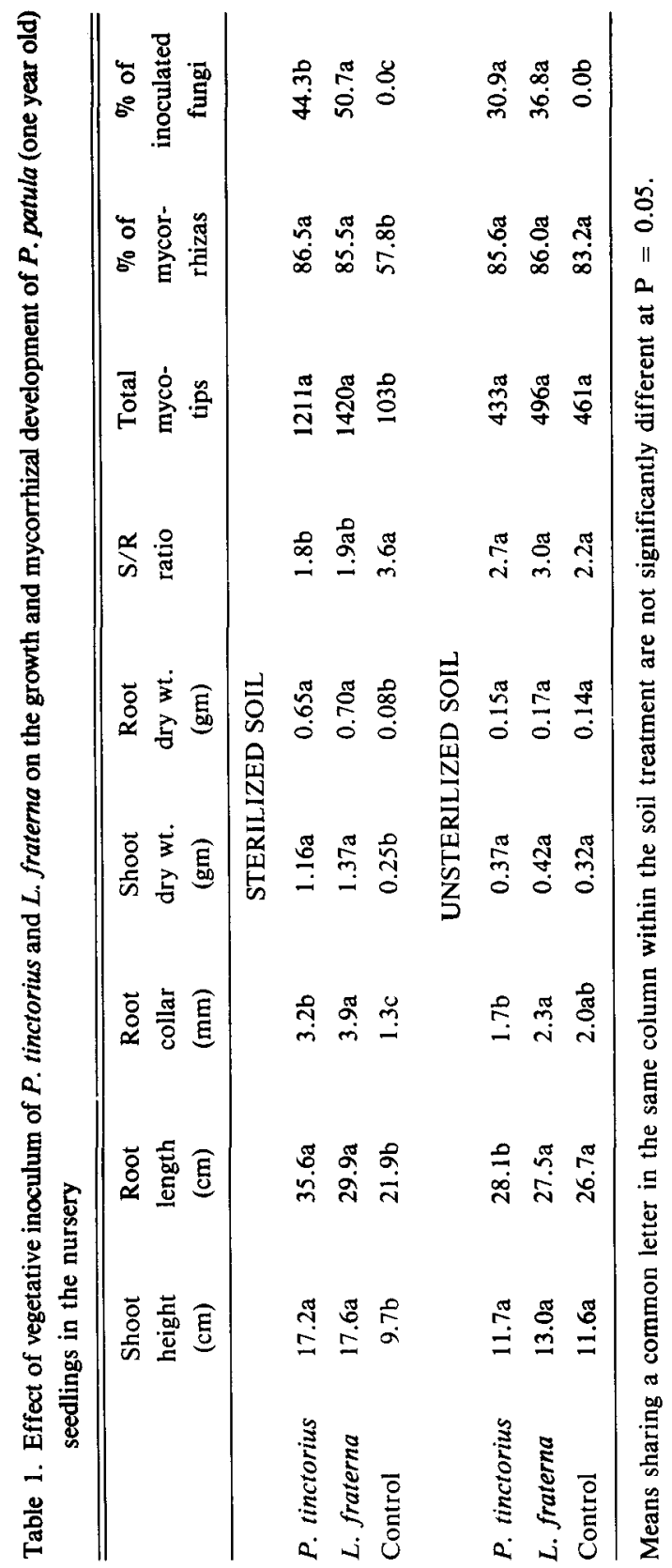


poor colonization of $P$. tinctorius in the nursery. Marx et al. (1970) reported that $P$. tinctorius grew rapidly at $28-30^{\circ} \mathrm{C}$ and capable of growing at $40-42^{\circ} \mathrm{C}$ in pure culture and formed more mycorrhizas with $P$. taede at $34^{\circ} \mathrm{C}$ than at lower temperatures. Marx and Bryan (1971) reported that aseptically grown $P$. taede seedlings with $P$. tinctorius ectomycorrhizae had better survival and growth at $40^{\circ} \mathrm{C}$ in laboratory tests than non-mycorrhizal seedlings or those mycorrhizal seedlings with $T$. terrestris. Temperature may be the main reason why $P$. tinctorius is not occurring in Nilgiri hills where the temperature ranges between 5 and $20^{\circ} \mathrm{C}$ during different parts of the year. The isolate of $P$. tinctorius used in the present study was obtained from the basidiomata associated with $E$. tereticornis in coastal Madras where the temperature in summer will raise up to $40^{\circ} \mathrm{C}$. Further research is needed to evaluate different environmental conditions on the growth and mycorrhizal development of $P$. patula by $P$. tinctorius. In spite of the positive growth response shown by the seedlings in the present study only further research will reveal whether these two fungi will survive when seedlings are outplanted since they are conspicuous by their absence in $P$. patula plantations in the Nilgiri hills.

\section{REFERENCES}

AOERER, R. 1986. Studies on ectomycorrhizae. II. Introducing remarks on characterization and identification. Mycotaxon, 26: 473-492.

KORNERUP, A. and J.H. WANSCHER. 1978. Methuen Handbook of Colour 3 rd ed. Methuen and Co. Ltd. London, p. 243.

MARX, D.H. 1991. The practical significance of ectomycorrhizae in forest establisment. In: Ecophysiology of ectomycorrhizae of forest trees. The Marcuswallenberg Foundation, Symposia proceedings, 7: 54-90.

MARX, D.H. and W.C. BRYAN. 1971. Influence of ectomycorrhizae on survival and growth of aseptic seedlings of loblolly pine at high temperature. For.Sci. 17: 37-41.

MARX, D.H. and W.C. BRYAN. 1975. Growth and ectomycorrhizal development of loblolly pine seedlings in fumigated soil infested with the fungal symbiont Pisolithus tinctorius. For. Sci. 21: 245- 254.

MARX, D.H. and C.E. CORDELL. 1987. Ecology and management of ectomycorrhizal fungi in regenerating forests in the eastern United States. In: Mycorrhizae in the Next Decade: Practical applications and research priorities. Seventh NACOM, May, 3-8, 1987. Gainesville, FL. Ed. D.M. Sylvia, L.L. hung and J.H. Graham. Int. of food and agric. Sciences, Univ. of Florida, Gainesville.

MARX, D.H., W.C. BRYAN and C.B. DAVEY. 1970. Influence of temperature on aseptic synthesis of ectomycorrhizae by Thelephora terrestris and Pisolithus tinctorius on loblolly pine. For. Sci. 16: 424431.

MARX, D.H., C.E. CORDELL, D.S. KENNEY, J.G. MEXAL, J.D. ARTMAN, J.W. RIFFLE and R.J. MOLINA. 1984. Commercial vegetative inoculum of Pisolithus tinctorius and inoculation techniques for development of ectomycorrhizae on bare-root tree seedlings. For. Sci. Monogr. 25: 1-101. 
NATARAJAN, K. 1977. South Indian Agaricales III. Kavaka. 5: 35-39.

SNEDECOR, G.W. and W.G. COCHRAN. 1967. Statistical Methods. The Iowa State University Press. Iowa USA p. 593.

TOMMERUP, I.e., N.L. BOUGHER and N. MALAJCZUK. 1991. Laccaria fraterna a common ectomycorr-hizal fungus with mono-and bisporic basidia and multinucleate spores: Comparison with quadri- sterigmate, binucleate spored L. laccata and the hypogeous relative Hydnangium cameum. Mycol. Res. 95: 689-698.

ZAK, B. 1973. Classification of ectomycorrhizae: In: Ectomycorrhizae: ecology and physiology. G.C. Marks and T.T. Kozlowski eds. Academic Press, New York and London, p. 43-78. 